\title{
Amylin Receptor Signaling in the Nucleus Accumbens Negatively Modulates $\mu$-opioid-Driven Feeding
}

\author{
Sarah K Baisley' and Brian A Baldo*,1,2 \\ 'Neuroscience Training Program, University of Wisconsin-Madison, Medical Sciences Center, University Ave Madison, WI, USA; ${ }^{2}$ Department of \\ Psychiatry University of Wisconsin-Madison, Research Park Blvd, Madison, WI, USA
}

\begin{abstract}
Amylin is a peptide co-secreted with insulin that penetrates into the brain, and produces satiation-like effects via actions in the brainstem, hypothalamus, and mesencephalon. Little is known, however, about the effects of amylin in the nucleus accumbens shell (AcbSh), where a circumscribed zone of intense amylin receptor (AMY-R) binding overlaps reported mappings of a 'hotspot' for $\mu$-opioid receptor ( $\mu$-OR) amplification of food reward. Here, the ability of intra-AcbSh AMY-R signaling to modulate $\mu$-OR-driven feeding was explored. Amylin ( I-30 ng) was administered with the $\mu$-OR agonist, D-Ala2, N-MePhe4, Gly-ol]-enkephalin (DAMGO) (0.25 $\mu$ g), directly into the AcbSh of ad libitum-maintained rats. Amylin dose-dependently reversed DAMGO-induced hyperphagia; 3 ng of amylin reduced DAMGO-mediated feeding by nearly $50 \%$. This dose was, however, completely ineffective at altering DAMGO-induced feeding in the anterior dorsal striatum. Intra-AcbSh amylin alone (3-30 ng) modestly suppressed 10\% sucrose intake in ad libitum-maintained rats, and chow in food-deprived rats, but only at the 30-ng dose. This result indicates that reversal of AcbSh DAMGO-induced feeding at a I0-fold lower dose was neither due to malaise nor motoric impairment. Finally, intra-AcbSh infusion of the AMY-R antagonist, ACI 87 (20 $\mu \mathrm{g})$, significantly attenuated the ability of prefeeding to suppress DAMGO-induced food intake, with no effects in non-prefed rats. Hence, AMY-R signaling negatively modulates $\mu$-OR-mediated appetitive responses at the level of the AcbSh. The results with $\mathrm{ACl} 87$ indicate that endogenous AMY-R transmission in the AcbSh curtails opioid function in the postprandial period, suggesting a novel pathway for peripheral-central integration in the control of appetitive motivation and opioid reward.

Neuropsychopharmacology (2014) 39, 3009-3017; doi:I0.1038/npp.2014.153; published online I3 August 2014
\end{abstract}

\section{INTRODUCTION}

Amylin, a 37-amino-acid peptide that belongs to the calcitonin gene-related peptide (CGRP) family (van Rossum et al, 1997), is co-secreted with insulin from pancreatic beta cells in coordination with prandial stimuli (Butler et al, 1990; Moore and Cooper, 1991; Ahren and Sundler, 1992). Once secreted, amylin modulates insulin's effects on glycogen synthesis and glucose uptake in muscle, and therefore has an important role in glycemic control (SinghFranco et al, 2011). In addition to these metabolic effects, amylin also modulates food intake via actions at multiple levels of the central nervous system (CNS). Amylin penetrates into the brain at least as well as insulin, and accumulates in sites throughout the neural axis (Banks and Kastin, 1998). Because CNS amylin receptors (AMY-Rs) show regional differences and localization to discrete neural pathways and structures, it is hypothesized that amylin and related peptides have a role in neuroregulation (Beaumont et al, 1993; Sexton

\footnotetext{
* Correspondence: Dr BA Baldo, Department of Psychiatry, University of Wisconsin-Madison, School of Medicine and Public Health, 600I Research Park Blvd, Madison, WI 53719 USA. Tel: + I 6082634019 , Fax: + 608265 3050, E-mail: babaldo@wisc.edu

Received 20 March 2014; revised 16 June 2014; accepted 17 June 2014; accepted article preview online 24 June 2014
}

et al, 1994; van Rossum et al, 1994; Christopoulos et al, 1995). Accordingly, AMY-R ligands cause a satiation-like suppression of feeding when infused into the lateral ventricle, third ventricle, hypothalamus, and ventral tegmental area (VTA) (Chance et al, 1991; Morley and Flood, 1991; Bouali et al, 1995; Lutz et al, 1998a; Rushing et al, 2000; Mietlicki-Baase et al, 2013). Perhaps the most extensively studied site for feeding-modulatory actions of amylin is the area postrema; blockade of area postrema AMY-Rs and lesions specific to the area postrema both attenuate the anorectic effect of systemically administered amylin (Lutz et al, 1998b, 2001; Mollet et al, 2004).

Less is known about feeding-modulatory effects of amylin in the telencephalon, despite the fact that one of the densest concentrations of high-affinity amylin-binding sites, and expression of component genes encoding the high-affinity AMY-R (Poyner et al, 2002) is found in the medial nucleus accumbens shell (AcbSh) (Sexton et al, 1994; van Rossum et al, 1994; Baisley et al, 2014). This zone of intense AMY-R binding conforms remarkably well with the circumscribed medial AcbSh area from which intense feeding responses are elicited by GABA or $\mu$-opioid receptor ( $\mu$-OR) stimulation (Bakshi and Kelley, 1993; Stratford and Kelley, 1997; Zhang and Kelley, 2000). Moreover, the reported 'hotspot' for amplification of hedonic taste reactions by $\mu$-OR stimulation (Pecina and Berridge, 2005) 
overlaps the AMY-R distribution. Because of this overlap, AcbSh-localized AMY-Rs are well-positioned to modulate food intake and hedonic taste reward by interacting with the $\mu$-opioid system.

To date, only one study (Baldo and Kelley, 2001) has investigated the role of AcbSh-localized AMY-Rs in controlling feeding behavior; this study showed that exogenously administered amylin in the 30-100 ng range suppressed feeding. Nevertheless, the interaction of AMY-Rs with other Acb-localized neuromodulator systems, and, importantly, the role of endogenous Acb AMY-R signaling in modulating feeding behavior, remain unknown. Here, interactions between AMY-Rs and $\mu$-ORs were studied, both in the AcbSh where dense AMY-R binding is found, and the anterior dorsal striatum (ADS), lacking high-affinity AMY$\mathrm{R}$ binding but where $\mu$-ORs also modulate feeding (Bakshi and Kelley, 1993; DiFeliceantonio et al, 2012). We also examined the effects of AMY-R blockade on $\mu$-OR-driven feeding, during either a food-deprived state or immediately after a prefeeding session (when circulating amylin levels are high) (Alam et al, 1992; Arnelo et al, 1998), to explore whether an endogenous 'tone' of AMY-R signaling at the level of the AcbSh interacts with the behavioral functions of $\mu$-ORs.

\section{MATERIALS AND METHODS}

\section{Subjects}

Subjects in all experiments were male Sprague-Dawley rats, obtained from Harlan (Madison, WI), weighing 300-325 g upon arrival at the laboratory. The rats were pair-housed in clear polycarbonate cages $(9.5$-inch width $\times 17$-inch length $\times 8$-inch height), with cob bedding, in a light- and temperature-controlled vivarium. Animals were maintained under a 12:12-h light-dark cycle (lights on at 7:00 AM). Food and water were available ad libitum, except as indicated for the various experiments. Animals were handled daily to reduce stress. Testing occurred between $1200-1800 \mathrm{~h}$. All facilities and procedures were in accordance with the guidelines regarding animal use and care put forth by the National Institutes of Health, and were supervised and approved by the Institutional Animal Care and Use Committee of the University of Wisconsin.

\section{Surgical Procedure}

Rats (weighing 300-325g) underwent stereotaxic surgery under isoflurane anesthesia according to standard techniques (Perry et al, 2009). Bilateral stainless-steel cannulae (10-mm long, 23 gauge) were aimed bilaterally either at the AcbSh or at the ADS and anchored in place with dental acrylic (New Truliner, Skokie, IL) and skull screws (Plastics One, Roanoke, VA). Surgeries were conducted with the nosebar set to $3.3 \mathrm{~mm}$ below interaural zero. For the AcbSh, the coordinates from bregma were: $+3.2-\mathrm{mm}$ anteroposterior (AP); \pm 1.0 -mm lateromedial (LM); and -5.2-mm dorsoventral (DV) (with injectors extending an additional $2.5 \mathrm{~mm}$ beyond cannulae tips for a final DV coordinate of -7.7). For ADS surgeries, the coordinates from bregma were: $+1.6 \mathrm{~mm} \mathrm{AP} ; \pm 2.4 \mathrm{~mm} \mathrm{LM}$; and $-1.7 \mathrm{~mm}$ DV (with injectors extending an additional
$2.5 \mathrm{~mm}$ beyond cannulae tips for a final DV coordinate of -4.2 ). Wire stylets (10-mm long, 30 gauge) were placed in the cannulae to prevent blockage. Animals were given an intramuscular injection of penicillin $(0.3 \mathrm{ml}$ of a $300000 \mathrm{U} /$ $\mathrm{ml}$ suspension; Phoenix Pharmaceuticals, St Joseph, MO), placed in a warm recovery cage, returned to their home cages on awakening, and given a recovery period of no $<5$ days (with daily health checks) before behavioral testing commenced.

\section{Drugs and Microinfusions}

Amylin (Bachem, Torrance, CA) and ([D-Ala2, N-MePhe4, Gly-ol]-enkephalin) (DAMGO) (Bachem) were dissolved in sterile isotonic saline, whereas AC187 (Tocris Bioscience, Ellisville, MO) was dissolved in sterile $\mathrm{H}_{2} \mathrm{O}$. The $0.25 \mu \mathrm{g} /$ $0.5 \mu \mathrm{l} /$ side dose of DAMGO was chosen because it has been shown to elicit robust feeding in satiated rats (eg, Perry et al, 2009). The dose of the AMY-R antagonist AC187 (Hay et al, 2005) was chosen because in our laboratory it altered prepulse inhibition upon intra-AcbSh infusion (Baisley et al, 2014). In other literature, an AC187 dose of $30 \mu \mathrm{g}$ but not $10 \mu \mathrm{g}$ delivered into lower levels of the CNS increased food intake in rats (Lutz et al, 1997; Mollet et al, 2004). Hence, the present experiment used an AC187 dose of $20 \mu \mathrm{g} / \mathrm{side}$. All three drugs were infused directly into specific brain regions in accordance with the experimental designs. For microinfusions, injectors (connected via tubing to a microdrive pump) extended $2.5 \mathrm{~mm}$ past cannulae tips, and delivered drugs at $0.32 \mu \mathrm{l} / \mathrm{min}$ over $1 \mathrm{~min} 33 \mathrm{~s}$, with a 1 -min postinfusion period before reinsertion of stylets and placement of rats into testing chambers.

\section{Experimental Design}

In all experiments, 30-min free-feeding test sessions were conducted in wire-bottom polycarbonate cages with rat chow pellets and water available, as previously described (Baldo and Kelley, 2001). Prior to all the experiments, rats were habituated to the testing cages to minimize stress. Testing occurred on every other day.

\section{Interactions between Amylin and DAMGO in the AcbSh}

Effects of amylin were tested in two dose ranges $(0,1,3 \mathrm{ng}$ and $0,10,30 \mathrm{ng}$ ), in separate groups of rats $(n=7$ for the low-dose range; $n=10$ for the high-dose range) to minimize the number of infusions per experiment. For both experiments, rats were surgically implanted with cannulae aimed at AcbSh. Rats were infused with saline or $0.25 \mu \mathrm{g} / 0.5 \mu \mathrm{l}$ DAMGO into the AcbSh 10 min before testing. Five minutes before testing, rats received a second infusion of saline or amylin into the AcbSh. DAMGO dose and amylin dose were both within-subjects factors; hence, each rat received all amylin doses with and without DAMGO (for a total of six infusions). Treatments were counterbalanced across test days according to Latin-square designs.

\section{Interactions between Amylin and DAMGO in the ADS}

The same basic protocol as Experiment 1 was followed, except rats $(n=6)$ were implanted with cannulae aimed at 
the ADS instead of the AcbSh. ADS coordinates were chosen based on prior literature describing a $\mu$-opioid-sensitive zone dorsal to the Acb (Bakshi and Kelley, 1993a; DiFeliceantonio et al, 2012). Rats received a total of four infusions.

\section{Effects of Intra-AcbSh Amylin (Without DAMGO) on Palatability- and Hunger-Induced Feeding}

Eight rats were used to test the effects of intra-AcbSh amylin upon sucrose intake in ad libitum-maintained rats. Prior to experimentation, the rats were exposed daily for 2 days to a $10 \%$ sucrose solution until they consumed a consistent amount over two 30-minute test sessions spaced $4 \mathrm{~h}$ apart. Once stable intake was achieved, rats were given intra-AcbSh infusion of amylin $(0,3,10,30 \mathrm{ng} / 0.5 \mu \mathrm{l} /$ side) administered according to a Latin-square design. Amylin was infused $5 \mathrm{~min}$ before testing, whereupon rats were placed into the testing cages for $30 \mathrm{~min}$ with free access to chow, water, and a bottle containing $10 \%$ sucrose. Seven of the eight rats in this experiment also underwent testing for intra-AcbSh amylin effects on hunger-driven chow intake. In this part of the experiment, rats were fooddeprived for $18 \mathrm{~h}$ prior to each testing period, given intraAcbSh amylin $(0,3,10,30 \mathrm{ng} / 0.5 \mu \mathrm{l})$ infusions, and placed into the testing cages for $30 \mathrm{~min}$ with rat chow and water present. The two experiments (sucrose intake and hungerdriven chow intake) were performed in a counterbalanced order, with half the rats receiving sucrose first, and the other half, hunger/chow intake first (for a total of eight infusions).

\section{Effects of AC187 on DAMGO-Induced Feeding, With or Without Prefeeding}

Seven rats were surgically prepared with cannulae aimed at the AcbSh. After recovery, rats underwent behavioral testing every other day for a total of eight test days. All rats were food-deprived for $18 \mathrm{~h}$ before each testing day; however, on each interim testing-free day, they had free access to food.

On each testing day, rats were either given a 30-min 'prefeeding' session, or given no prefeeding session, whereupon they received intra-AcbSh infusions of DAMGO and AC187. DAMGO $(0,0.25 \mu \mathrm{g} / 0.5 \mu \mathrm{l})$ was infused bilaterally into the AcbSh 10 min before testing, followed 5 min later by an infusion of AC187 $(0,20 \mu \mathrm{g} / 0.5 \mu \mathrm{l})$. For rats exposed to the prefeeding session, infusions were given after the prefeeding session, and the time between the prefeeding and testing session was $15 \mathrm{~min}$. The environmental contexts for prefed and non-prefed rats were identical. Following drug infusions, both prefed and non-prefed rats were tested in a 30-min feeding sessions. Each rat received all treatment combinations (mock/mock, DAMGO/mock, mock/AC187, DAMGO/AC187) under both prefed and non-prefed conditions, according to a within-subjects, Latin-square design. 'Mock' infusions were used to limit the number of needle insertions into the tissue of the AcbSh and therefore reduce tissue damage. Ten-millimeter injectors that did not protrude beyond the ends of the guide cannulae were lowered into the cannulae for $2 \mathrm{~min}$ and $33 \mathrm{~s}$ to mimic a saline infusion. Not including mock infusions, each rat received a total of eight infusions.

\section{Data Analysis}

Multifactor ANOVAs were used for all experiments. Significant main effects or interactions were followed by Fisher's PLSD post hoc. Experimenters blind to data and treatments confirmed injector placements in Nissl-stained sections. Final sample sizes exclude rats with placements outside of target sites.

\section{RESULTS}

Figure 1 depicts histological verification of intra-tissue injection placements. One rat was removed from Experiment 1 owing to placements that fell outside of the targeted region. Representative photomicrographs of injector placements into the AcbSh and ADS of cannulated animals reveal that cannulae and injector tracks are clearly visible with no unusual damage to the targeted areas. For Acb placements, although in some cases we would notice some damage to the lateral ventricles induced by the guide cannulae, injector tips were found always to be located within the cellular neuropil of the AcbSh (not in the ventricles).

\section{Amylin Potently Reduced Intra-AcbSh DAMGO-Induced Feeding}

As shown in Figure 2, DAMGO significantly elevated feeding in both the low-dose and high-dose DAMGO/ amylin interaction studies (main effect of DAMGO: $\mathrm{F}(1,6)=50.7, P<0.001$ for low-dose study; $\mathrm{F}(1,9)=17.9$, $P<0.01$ for high-dose study). Post hoc comparison among means with Fisher's PLSD test confirmed that DAMGOassociated levels of food intake were significantly elevated relative to saline or to any of the amylin-alone doses (Ps $=0.0001-0.05)$.

In both dose ranges tested, amylin significantly attenuated DAMGO-induced hyperphagia (DAMGO $\times$ amylin interactions: $\mathrm{F}(2,12)=4.8, P<0.05$ for low-dose study; $\mathrm{F}(2,18)=6.6, P<0.01$ for high-dose study). Post hoc comparison among means revealed specific differences between DAMGO/saline and DAMGO/amylin-3 ng, DAMGO/amylin-10 ng, and DAMGO/amylin-30 ng dose-combinations (Figure 2a and $\mathrm{b}$ ). Note that these doses of amylin did not suppress feeding when tested in the absence of DAMGO, as indicated by the lack of significant differences between vehicle-treated rats and any of the amylin-alone doses (although there was a small, nonsignificant trend at the highest dose, $30 \mathrm{ng}$ ). Moreover, amylin (either alone or in combination with DAMGO) did not affect water intake in either the high-dose or low-dose experiment, as evidenced by the lack of amylin main effects or amylin $\times$ DAMGO interactions $(F s=0.23-2.5$, not significant (NS)). Hence, the potent reversal of DAMGO-driven feeding by amylin, particularly at the low, 3-ng amylin dose, was unlikely the result of nonspecific motor impairment or malaise. It should be noted that for the group that received lower doses of amylin, baseline saline/saline and DAMGO/saline feeding values were higher relative to those for the group that received higher doses of amylin. However, there were no systematic differences in injector tip placements or methodology across groups. These differing values may 

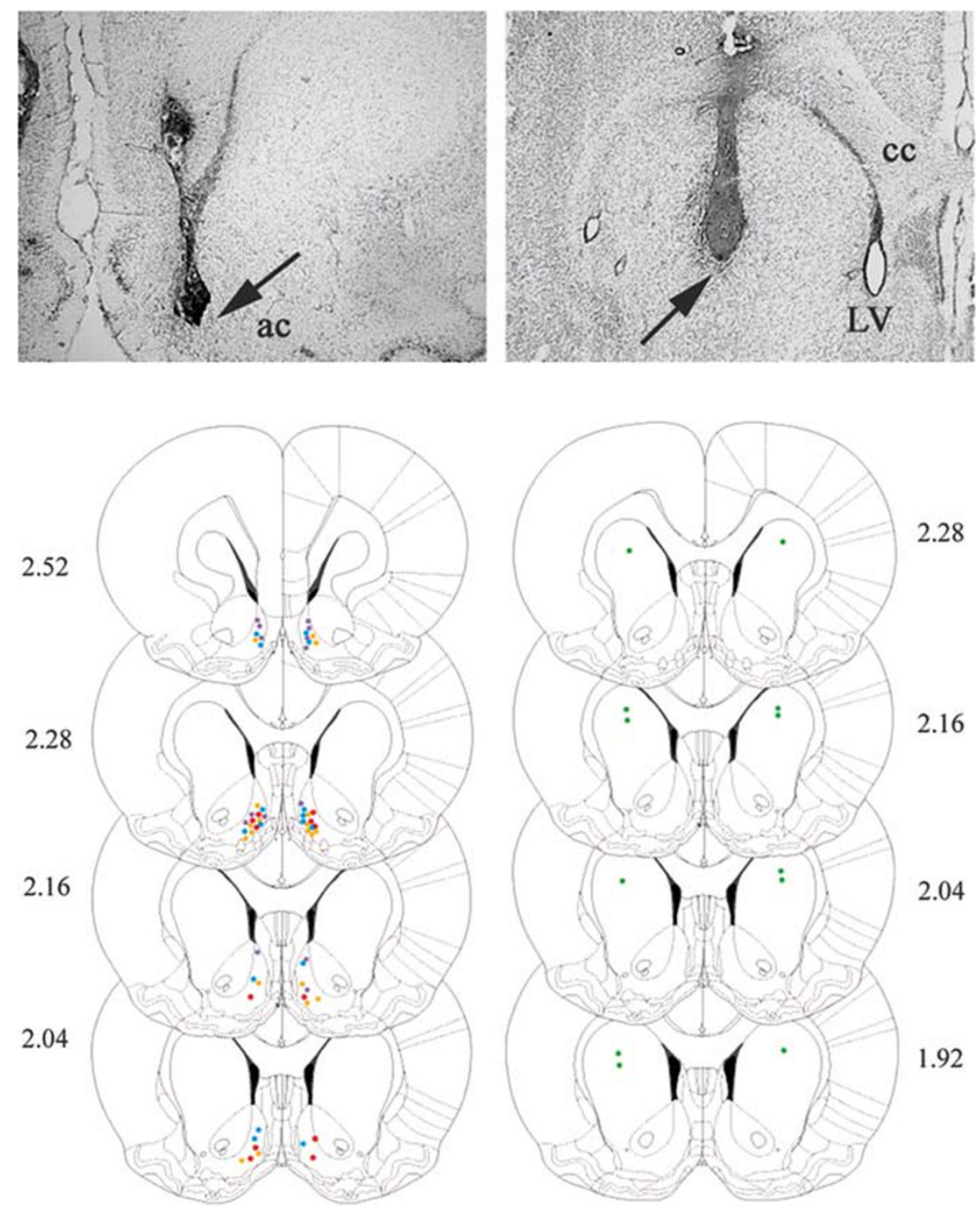

Figure I Injector placements for accumbens shell (AcbSh) and anterior dorsal striatum (ADS)-cannulated animals. Photomicrographs at the top of each column show injector placements into the AcbSh (left) and ADS (right). Arrows indicate location of injector tips. Below the photomicrographs, line drawings of coronal sections (with position of each section given in $\mathrm{mm}$ from bregma) show injection sites from rats with bilateral placements in AcbSh and ADS. Each injector tip placement is represented by a dot color-coded by experiment; red and orange represent low-dose and high-dose amylin vs DAMGO experiments, respectively; green represents the ADS study; blue represents hunger- and palatability-driven feeding; violet represents the ACI87/ prefeeding study. ac, anterior commissure; cc, corpus callosum; LV, lateral ventricle. Line drawings were adapted from the atlas of Paxinos and Watson (2007), with permission.

have been due to normally occurring, between-cohort differences across separate groups of rats.

\section{Amylin Did Not Alter Intra-ADS DAMGO-Induced Feeding}

It has been shown that, outside the Acb, a zone within the ADS also subserves $\mu$-opioid-driven feeding (Bakshi and Kelley, 1993; DiFeliceantonio et al, 2012). We replicated this observation, obtaining a main effect of DAMGO in the ADS $(\mathrm{F}(1,5)=39.749, P<0.01)$ on food intake (see Figure $2 \mathrm{~b}$, inset). In contrast to the AcbSh, there was no significant main effect of 3-ng amylin in the ADS on food intake nor on $\mathrm{DAMGO} \times$ amylin interaction $(F s=1.5-2.0, \mathrm{NS})$. Amylin also failed to alter water intake, as evidenced by lack of an amylin main effect or amylin $\times$ DAMGO interaction ( $F s=0.6-0.7, \mathrm{NS})$. Therefore, the same dose of amylin that reduced the effects of DAMGO on food intake by nearly $50 \%$ in the AcbSh was ineffective at reducing DAMGOinduced feeding in the ADS.

\section{In a Higher Dose Range, Intra-AcbSh Amylin Modestly Decreased Hunger- or Palatability-Induced Feeding (Without DAMGO)}

There was no main effect of AcbSh amylin on sucrose intake $(\mathrm{F}(3,21)=1.9, \mathrm{NS})$, although a directed contrast showed a significant difference between the saline condition and the Amylin 30-ng condition, with the Amylin 30-ng condition slightly suppressing sucrose intake $(P<0.05$, Figure $3 a)$. However, amylin failed to alter water intake in this experiment $(F(3,21)=0.7, N S)$. AcbSh amylin had a significant main effect on chow intake in food-deprived rats $(\mathrm{F}(3,18)=$ 4.2, $P<0.02$ ) (see Figure $3 \mathrm{~b}$ ). Post hoc tests showed a 

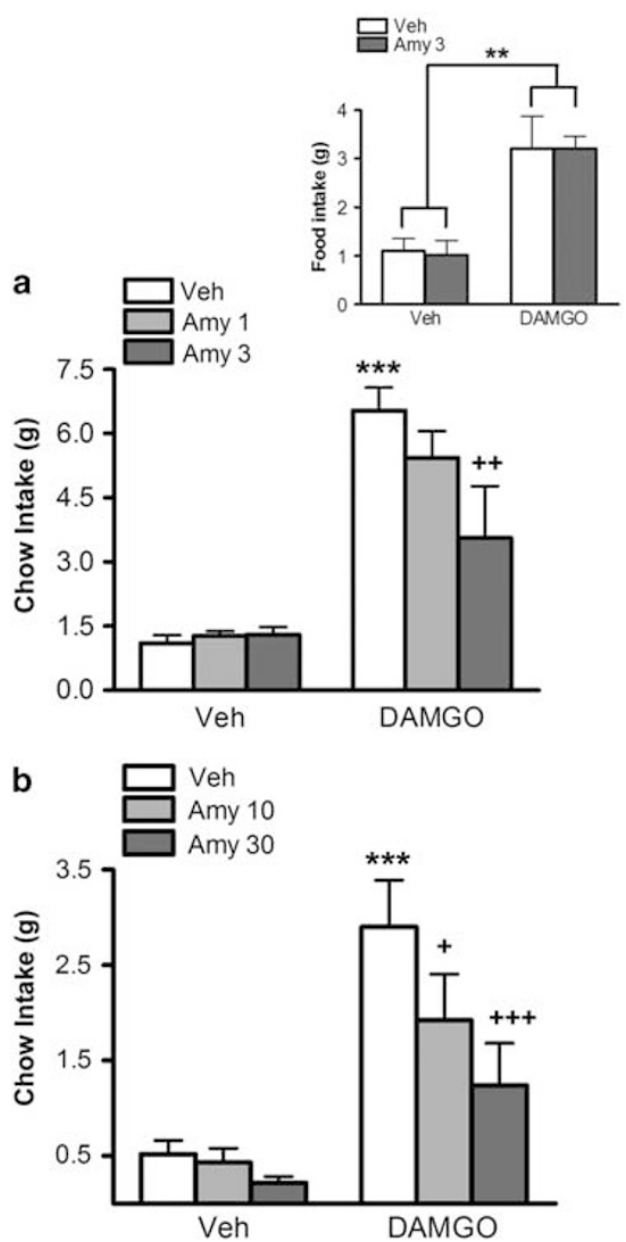

Figure 2 (a) The effects of intra-accumbens shell (AcbSh) amylin (Vehicle (Veh), I, or $3 \mathrm{ng}$ ) on chow intake elicited by intra-AcbSh DAMGO (Veh or $0.25 \mu \mathrm{g})$. ${ }^{*} * * P<0.00$ I compared with Veh/Veh. ${ }^{+}+P<0.0$ I compared with Veh/DAMGO. Inset: Interaction between DAMGO (Veh or $0.25 \mu \mathrm{g}$ ) and amylin (Veh or $3 \mathrm{ng}$ ) upon infusion of both compounds into the anterior dorsal striaum (ADS). ${ }^{*} * P<0.01$, main effect of DAMGO. (b) Interaction between higher doses of amylin (Veh, 10, or $30 \mathrm{ng}$ ) and DAMGO (Veh or $0.25 \mu \mathrm{g}$ ) upon infusion of both compounds into the AcbSh. ${ }^{*} * * *<0.01$, compared with $V e h / V e h .{ }^{+} p<0.05,{ }^{+}+++P<0.00$ I compared with Veh/DAMGO. All testing sessions were 30-min long. Error bars depict one SEM.

significant difference between the saline and amylin 30-ng conditions $(P<0.01)$, but not between saline and other amylin doses. This was the only experiment in which amylin affected water intake $(\mathrm{F}(3,18)=3.3, P<0.05)$, producing a significant $(50 \%)$ decrease at the 30 -ng dose $(P<0.008)$. No other dose significantly altered water intake. These results further indicate that the reversal of DAMGOinduced feeding by substantially lower amylin doses (as observed in the aforementioned experiments) was not the consequence of a nonspecific motivational or motoric impairment.

Intra-AcbSh AMY-R Blockade Significantly Reversed the Ability of Prefeeding to Suppress DAMGO-Induced Food Intake

As expected, food-deprived rats that were given a 30-min chow prefeeding session 15 min prior to the 30 -min chow testing session ate less than rats that were not prefed (main effect of prefeeding: $\mathrm{F}(1,6)=24.8, P<0.003)$. Also, DAMGO had a significant main effect on food intake in both prefed and non-prefed rats $(F(1,6)=268.2, P<0.0001)$. Again, as expected, DAMGO-induced hyperphagia was lower after prefeeding $(P<0.0001$, Figure 4$)$. There was a significant interaction between DAMGO and the AMY-R antagonist, AC187 $(\mathrm{F}(1,6)=6.1, P<0.05)$. Comparisons among means revealed a significant difference between the prefed/ DAMGO condition compared with the prefed/DAMGO/ AC187 condition $(P<0.05)$, with rats in the latter condition eating more, thus demonstrating that blocking AMY-Rs partly reverses the ability of prefeeding to diminish $\mu$-opioid-driven food intake (Figure 4). Interestingly, AC187 did not augment feeding in rats not treated with DAMGO, suggesting that the modulatory effect of endogenous AcbSh AMY-R signaling exhibits some specificity for excessive, mu-opioid-driven appetitive responses. For additional means comparisons, see Figure 4 legend. For water intake, there was no significant main effect of AC187, AC187 $\times$ DAMGO interaction, or feeding-status $\times$ AC187 $\times$ DAMGO interaction ( $F s=0.02-3.2, \mathrm{NS})$.

To explore the possibility of carry-over effects arising from repeated exposure to food-restriction over the course of the experiment, we conducted directed comparisons with $t$-tests on sub-cohorts of rats receiving various treatments either in the first half (days 1-4) or second half (days 5-8) of the experiment (recall that the order of treatments was counterbalanced across subjects). The following treatments were analyzed with regard to possible differences in the first vs second half: DAMGO, DAMGO + prefeeding, DAMGO + AC187, DAMGO + AC187 + prefeeding. These comparisons revealed no effect of treatment order ( $t s=0.12-0.9, \mathrm{NS})$, indicating a lack of carry-over effects over the duration of the experiment.

\section{DISCUSSION}

These results show for the first time a potent modulatory influence of AMY-R signaling on $\mu$-OR-mediated responses at the level of the AcbSh. Our results demonstrate that stimulating AMY-Rs with exogenously administered amylin strongly reduces $\mu$-OR agonist-induced feeding at doses considerably lower than those required to even modestly diminish either hunger-associated chow intake or palatable feeding (sucrose drinking). Moreover, blockade of AMY-Rs partly reversed the ability of prefeeding to suppress intake engendered by intra-AcbSh DAMGO. Together, these results reveal a potent negative modulation of $\mu$-ORs by both exogenous and endogenous AMY-R signaling, and show for the first time a role of endogenous AMY-R ligands in post-meal-feeding modulation at the level of the AcbSh.

The reversal of DAMGO-associated feeding seen in the present study ranks among the most potent of the behavioral effects of amylin obtained from anywhere in the brain. The lowest dose of exogenously administered, intra-AcbSh amylin to significantly reduce DAMGO-driven feeding was $3 \mathrm{ng} / \mathrm{side}$, or $6 \mathrm{ng} / \mathrm{rat}(1.52 \mathrm{pmol} / \mathrm{rat})$. This dose is similar to that required to suppress feeding upon infusion into the third ventricle, immediately adjacent to the medial basal hypothalamus (1 pmol/rat; Rushing et al, 2000), and 

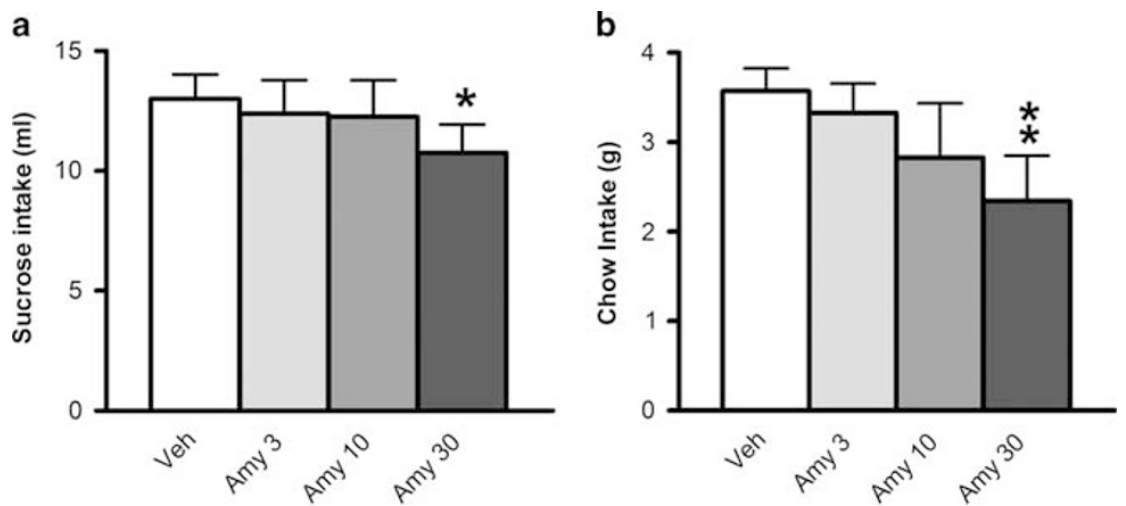

Figure 3 (a) The effects of intra-accumbens shell (AcbSh) amylin (Amy), (vehicle (Veh), 3, 10 or 30 ng) on intake of a 10\% sucrose solution. *P<0.05, compared with Veh condition. (b) Effects of intra-AcbSh Amy (Veh, 3, I0, or $30 \mathrm{ng}$ ) in I8-h food-deprived rats during a 30-minute testing session. *** $<$ <.0 I compared with Veh condition. DAMGO was not given in either experiment. All testing sessions were 30-min long. Error bars depict one SEM.

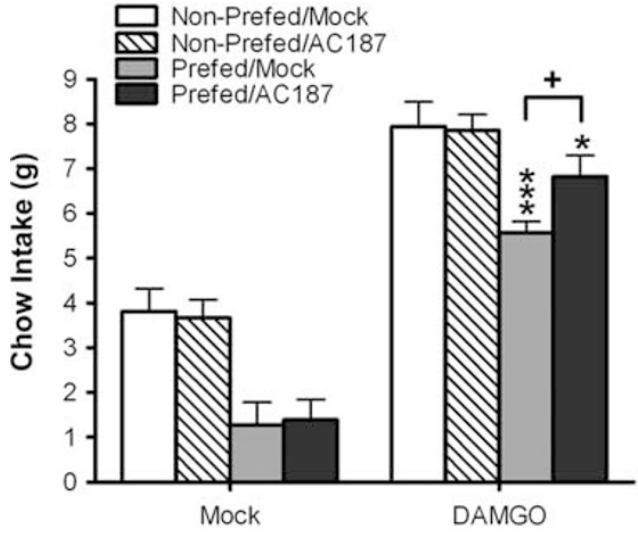

Figure 4 The effects of intra-accumbens shell (AcbSh) infusions of DAMGO $(0.25 \mu \mathrm{g})$ plus $\mathrm{ACl} 87(20 \mu \mathrm{g})$ combinations on chow intake in grams (g) during 30 min testing sessions. All rats were food-deprived for $18 \mathrm{~h}$. Non-prefed rats were given either drug or 'mock' infusions (see text) directly before the $30 \mathrm{~min}$ feeding test session. Prefed rats ate chow in a 30 min prefeeding session, were given drug infusions, and then were tested in a second 30-min feeding session. See text for further methodological details. Values represent means \pm SEM. $* P<0.05$, $* * * P<0.001$ compared with Non-Prefed/DAMGO/Mock condition. ${ }^{+} P<0.05$ between the Prefed/DAMGO/Mock and Prefed/DAMGO/ACI 87 conditions.

even lower than the dose required to reduce feeding in the area postrema, where $10 \mathrm{pmol} / \mathrm{rat}$ amylin is effective but $1 \mathrm{pmol} / \mathrm{rat}$ is not (Mollet et al, 2004). We also found that the 3-ng/side amylin dose, which robustly suppressed DAMGOinduced feeding in the AcbSh, was completely ineffective at altering DAMGO-driven feeding in the ADS. It has been shown that $\mu$-OR stimulation outside the Acb, in select dorsal striatal regions, increases feeding (Bakshi and Kelley, 1993a; DiFeliceantonio et al, 2012). However, these striatal territories possess neither AMY-R binding nor expression of AMY-R-component genes (Sexton et al, 1994; van Rossum et al, 1994; Baisley et al, 2014). Therefore, our results indicate that DAMGO-induced hyperphagia is only reduced when amylin is infused into striatal regions rich in AMY-R receptors, suggesting that targeting this receptor may represent a mechanism for modulating opioid effects in the ventral striatum specifically.
Interestingly, we found that intra-AcbSh amylin was considerably less potent in its modulation of sucrose drinking, compared with its effects on DAMGO-driven feeding; a 30-ng amylin dose was required to produce a small reduction in sucrose intake, 10 -fold higher than that required to significantly reverse DAMGO-associated feeding. The 30-ng dose is within the parameters reported in the only prior study of intra-Acb amylin infusion on hungerassociated chow intake (Baldo and Kelley, 2001), and is also consistent with results shown in the present study for hunger-driven feeding. Considering the evidence that $\mu$-opioid signaling in the Acb robustly modulates palatable feeding (Zhang and Kelley, 1997; Pecina and Berridge, 2005; Woolley et al, 2006), our initial hypothesis was that amylin would reverse sucrose intake in a dose range closer to that observed for the negative modulation of DAMGO effects. It is worth considering, however, that whereas intra-AcbSh DAMGO infusions affect $\mu$-ORs only in that structure, sucrose drinking may recruit $\mu$-opioid transmission in multiple redundant sites (Koch et al, 1995; Kim et al, 2004; Smith and Berridge, 2007; Denbleyker et al, 2009). Therefore, amylin actions (in the dose range tested) in the AcbSh may not be sufficient to reduce sucrose solution intake beyond the modest degree seen here. Accordingly, Kelley et al (1996) found that intra-Acb infusions of naloxone or naltrexone effectively reduced sucrose drinking, but only by about $20 \%$. Moreover, whereas intra-AcbSh naloxone did not significantly reduce chow intake, there was a trend towards a reduction of about $15 \%$. Hence, the present results with amylin are not inconsistent with these opioid antagonist findings, in the sense that both intra-Acb stimulation of AMY-Rs, and blockade of opioid receptors, reduced modestly, but did not eliminate, both sucrose intake and hunger-driven feeding.

To explore the role of endogenous AMY-R signaling, we tested the ability of prefeeding to suppress AcbSh DAMGOinduced hyperphagia either with or without intra-AcbSh infusions of the AMY-R antagonist, AC187 (Hay et al, 2005). Intra-AcbSh AC187 significantly reversed the ability of prefeeding to suppress DAMGO-induced food intake; however, this treatment did not alter food intake in nonDAMGO-treated rats, nor did it elevate DAMGO-induced feeding in non-prefed rats. These results suggest some 
degree of specificity of AMY-R modulation for $\mu$-opioid function. One possible explanation for these effects is that the AMY-R ligands that negatively modulate $\mu$-OR responses fluctuate according to prandial stimuli, with the highest levels occurring in the postprandial period. One candidate ligand is peripherally secreted amylin, which is co-released with insulin in response to feeding and macronutrient flux (Ogawa et al, 1990; Arnelo et al, 1998). According to this hypothesis, prefed rats could have higher amylin levels than the non-prefed rats and this elevated amylin 'tone' may underlie the reduction of opioid-driven feeding in the early postprandial period. Given that the nonprefed, food-deprived rats likely had lower levels of amylin, the lack of AC187 effect in non-prefed rats (DAMGO-treated or otherwise) could reflect a paucity of endogenous ligand in the Acb, and, consequently, negligible levels of endogenous AMY-R signaling to block. The question arises, however, as to whether sufficient levels of amylin cross the blood-brain barrier to enact behavioral effects. Studies with radiolabeled peptides showed that intact amylin accumulates in multiple brain structures, including the striatum, after systemic injection in mice, possibly via a saturable transport mechanism. Indeed, amylin showed greater overall brain penetrance that insulin (Banks and Kastin, 1998). Nevertheless, caution should be used in interpreting these results, as only a small fraction of the systemically administered amylin reached the brain and the striatum was among the sites showing relatively lower levels of amylin accumulation. A more definitive answer awaits detailed analysis of real-time amylin flux in the Acb, using sensitive mass spectrometry-based methods. Another possibility (though not mutually exclusive) is that the endogenous AMY-R ligand is CGRP. There are appreciable densities of CGRP-like immunoreactive fibers in the Acb, and relatively high densities of CGRP binding (Kruger et al, 1988; van Rossum et al, 1997). CGRP binds to the Acb-localized AMY-R, albeit with less affinity than amylin (Beaumont et al, 1993). Hence, it is possible that either CGRP, amylin, or a combination of both ligands participate in postprandial $\mu$-OR modulation through AMY-Rs. Further studies are needed to clarify this issue. Regardless, the present results clearly indicate for the first time that there is a negativemodulatory interaction between endogenous AMY-R and $\mu$-opioid systems at the level of the AcbSh; this interaction is revealed immediately following a meal.

Note that the lack of AC187-induced feeding augmentation in DAMGO-treated, non-prefed rats could be attributed to a ceiling effect. However, close examination of intake levels in individual rats shows that roughly half of the rats ate more during the food deprivation + DAMGO + AC187 condition relative to food deprivation + DAMGO-including the rat exhibiting the highest intake score under DAMGO alone-whereas the other half ate less (data not shown). This pattern would tend to argue against the idea that there was no room to move upward under the nonprefed-DAMGO + AC187 condition.

Presently, the mechanism underlying AMY-R and $\mu$-OR interaction is unknown. However, it is interesting to consider that the high-affinity AMY-1 receptor is a G-protein coupled receptor that increases intracellular cAMP levels, and that $\mu$-ORs are coupled to $\mathrm{G}(\mathrm{i})$-proteins, which decrease intracellular cAMP levels (Morfis et al, 2008; Williams et al,
2013). Therefore, it is possible that the AMY-Rs may negatively modulate $\mu$-ORs via interactions between postreceptor cAMP-dependent transduction pathways.

Clinically, our results may be relevant to disorders such as binge-eating disorder and bulimia nervosa. Mu-opioid signaling in the CNS is implicated in both disorders; accordingly, there is some evidence that opioid-blocking drugs (including selective $\mu$-OR antagonists) ameliorate at least some symptoms of these disorders, and an association has been reported between binge-eating disorder and a gain-of-function polymorphism of the $\mu$-OR gene (Marrazzi et al, 1995; Davis et al, 2009; Berner et al, 2011; Ziauddeen et al, 2013). A theoretical framework has been proposed stating that intra-Acb $\mu$-OR signaling acts to extend feeding (particularly on palatable foods) beyond physiological need, resulting in excess caloric intake (Kelley et al, 2005). Hence, in addition to its established clinical role in the regulation of Type 2 diabetes mellitus, the FDAapproved amylin analog, Pramlintide, may be useful treatment for excessive, $\mu$-opioid-driven non-homeostatic palatable feeding, as occurs putatively in pathological conditions such as binge-type eating disorders and obesity. Beyond feeding, AMY-R-based drugs may have therapeutic effects in opiate and alcohol craving, conditions in which both the Acb, and $\mu$-OR transmission, have been implicated (O’Brien, 2005).

In summary, this is the first study to examine interactions between AcbSh $\mu$-ORs and amylin. We find that AMY-R signaling enacts robust negative modulation over $\mu$-ORmediated responses, highlighting a novel receptor-based mechanism with which to modulate central $\mu$-OR signaling in multiple 'disorders of appetitive motivation,' including, but not limited to, psychiatric disorders with binge features.

\section{FUNDING AND DISCLOSURE}

The authors declare no conflict of interest.

\section{ACKNOWLEDGEMENTS}

This work was supported by R21 MH093824 (BAB), and SKB was supported by training grant T32 GM007507. We are grateful to Ken Sadeghian and Ryan Selleck for technical assistance. Facilities and procedures complied with animal use and care guidelines from the National Institutes of Health of the USA, and were approved by the Institutional Animal Care and Use Committee of the University of Wisconsin.

\section{REFERENCES}

Ahren B, Sundler F (1992). Localization of calcitonin gene-related peptide and islet amyloid polypeptide in the rat and mouse pancreas. Cell Tissue Res 269: 315-322.

Alam T, Chen L, Ogawa A, Leffert JD, Unger RH, Luskey KL (1992). Coordinate regulation of amylin and insulin expression in response to hypoglycemia and fasting. Diabetes 41: 508-514.

Arnelo U, Reidelberger R, Adrian TE, Larsson J, Permert J (1998). Sufficiency of postprandial plasma levels of islet amyloid polypeptide for suppression of feeding in rats. Am J Physiol 275: R1537-R1542. 
Baisley SK, Bremer QZ, Bakshi VP, Baldo BA (2014). Antipsychotic-like actions of the satiety peptide, amylin, in ventral striatal regions marked by overlapping calcitonin receptor and RAMP-1 gene expression. J Neurosci 34: 4318-4325.

Bakshi VP, Kelley AE (1993). Striatal regulation of morphineinduced hyperphagia: an anatomical mapping study. Psychopharmacology (Berl) 111: 207-214.

Baldo BA, Kelley AE (2001). Amylin infusion into rat nucleus accumbens potently depresses motor activity and ingestive behavior. Am J Physiol Regul Integr Comp Physiol 281: R1232-R1242.

Banks WA, Kastin AJ (1998). Differential permeability of the blood-brain barrier to two pancreatic peptides: insulin and amylin. Peptides 19: 883-889.

Beaumont K, Kenney MA, Young AA, Rink TJ (1993). High affinity amylin binding sites in rat brain. Mol Pharmacol 44: 493-497.

Berner LA, Bocarsly ME, Hoebel BG, Avena NM (2011). Pharmacological interventions for binge eating: lessons from animal models, current treatments, and future directions. Curr Pharm Des 17: 1180-1187.

Bouali SM, Wimalawansa SJ, Jolicoeur FB (1995). In vivo central actions of rat amylin. Regul Pept 56: 167-174.

Butler PC, Chou J, Carter WB, Wang YN, Bu BH, Chang D et al (1990). Effects of meal ingestion on plasma amylin concentration in NIDDM and nondiabetic humans. Diabetes 39: 752-756.

Chance WT, Balasubramaniam A, Zhang FS, Wimalawansa SJ, Fischer JE (1991). Anorexia following the intrahypothalamic administration of amylin. Brain Res 539: 352-354.

Christopoulos G, Paxinos G, Huang XF, Beaumont K, Toga AW, Sexton PM (1995). Comparative distribution of receptors for amylin and the related peptides calcitonin gene related peptide and calcitonin in rat and monkey brain. Can J Physiol Pharmacol 73: 1037-1041.

Davis CA, Levitan RD, Reid C, Carter JC, Kaplan AS, Patte KA et al (2009). Dopamine for 'wanting' and opioids for 'liking': a comparison of obese adults with and without binge eating. Obesity (Silver Spring) 17: 1220-1225.

Denbleyker M, Nicklous DM, Wagner PJ, Ward HG, Simansky KJ (2009). Activating mu-opioid receptors in the lateral parabrachial nucleus increases c-Fos expression in forebrain areas associated with caloric regulation, reward and cognition. Neuroscience 162: 224-233.

DiFeliceantonio AG, Mabrouk OS, Kennedy RT, Berridge KC (2012). Enkephalin surges in dorsal neostriatum as a signal to eat. Curr Biol 22: 1918-1924.

Hay DL, Christopoulos G, Christopoulos A, Poyner DR, Sexton PM (2005). Pharmacological discrimination of calcitonin receptor: receptor activity-modifying protein complexes. Mol Pharmacol 67: 1655-1665.

Kelley AE, Baldo BA, Pratt WE (2005). A proposed hypothalamicthalamic-striatal axis for the integration of energy balance, arousal, and food reward. J Comp Neurol 493: 72-85.

Kelley AE, Bless EP, Swanson CJ (1996). Investigation of the effects of opiate antagonists infused into the nucleus accumbens on feeding and sucrose drinking in rats. J Pharmacol Exp Ther 278: 1499-1507.

Kim EM, Quinn JG, Levine AS, O'Hare E (2004). A bi-directional mu-opioid-opioid connection between the nucleus of the accumbens shell and the central nucleus of the amygdala in the rat. Brain Res 1029: 135-139.

Koch JE, Glass MJ, Cooper ML, Bodnar RJ (1995). Alterations in deprivation, glucoprivic and sucrose intake following general, $\mathrm{mu}$ and kappa opioid antagonists in the hypothalamic paraventricular nucleus of rats. Neuroscience 66: 951-957.

Kruger L, Mantyh PW, Sternini C, Brecha NC, Mantyh CR (1988). Calcitonin gene-related peptide (CGRP) in the rat central nervous system: patterns of immunoreactivity and receptor binding sites. Brain Res 463: 223-244.
Lutz TA, Mollet A, Rushing PA, Riediger T, Scharrer E (2001). The anorectic effect of a chronic peripheral infusion of amylin is abolished in area postrema/nucleus of the solitary tract (AP/ NTS) lesioned rats. Int J Obes Relat Metab Disord 25: 1005-1011.

Lutz TA, Rossi R, Althaus J, Del Prete E, Scharrer E (1997). Evidence for a physiological role of central calcitonin generelated peptide (CGRP) receptors in the control of food intake in rats. Neurosci Lett 230: 159-162.

Lutz TA, Rossi R, Althaus J, Del Prete E, Scharrer E (1998a). Amylin reduces food intake more potently than calcitonin generelated peptide (CGRP) when injected into the lateral brain ventricle in rats. Peptides 19: 1533-1540.

Lutz TA, Senn M, Althaus J, Del Prete E, Ehrensperger F, Scharrer E (1998b). Lesion of the area postrema/nucleus of the solitary tract (AP/NTS) attenuates the anorectic effects of amylin and calcitonin gene-related peptide (CGRP) in rats. Peptides 19: 309-317.

Marrazzi MA, Bacon JP, Kinzie J, Luby ED (1995). Naltrexone use in the treatment of anorexia nervosa and bulemia nervosa. Int Clin Psychopharmacol 10: 163-172.

Mietlicki-Baase EG, Rupprecht LE, Olivos DR, Zimmer DJ, Alter $\mathrm{MD}$, Pierce RC et al (2013). Amylin receptor signaling in the ventral tegmental area is physiologically relevant for the control of food intake. Neuropsychopharmacology 38: 1685-1697.

Mollet A, Gilg S, Riediger T, Lutz TA (2004). Infusion of the amylin antagonist AC 187 into the area postrema increases food intake in rats. Physiol Behav 81: 149-155.

Moore CX, Cooper GJ (1991). Co-secretion of amylin and insulin from cultured islet beta-cells: modulation by nutrient secretagogues, islet hormones and hypoglycemic agents. Biochem Biophys Res Commun 179: 1-9.

Morfis M, Tilakaratne N, Furness SG, Christopoulos G, Werry TD, Christopoulos A et al (2008). Receptor activity-modifying proteins differentially modulate the $G$ protein-coupling efficiency of amylin receptors. Endocrinology 149: 5423-5431.

Morley JE, Flood JF (1991). Amylin decreases food intake in mice. Peptides 12: 865-869.

Ogawa A, Harris V, McCorkle SK, Unger RH, Luskey KL (1990). Amylin secretion from the rat pancreas and its selective loss after streptozotocin treatment. J Clin Invest 85: 973-976.

O'Brien CP (2005). Anticraving medications and relapse prevention: a possible new class of psychoactive medications. Am J Psychiat 162: 1423-1431.

Paxinos G, Watson C (2007). The rat brain in stereotaxic coordinates, 6th edn, Academic Press.

Pecina S, Berridge KC (2005). Hedonic hot spot in nucleus accumbens shell: where do mu-opioids cause increased hedonic impact of sweetness? J Neurosci 25: 11777-11786.

Perry ML, Baldo BA, Andrzejewski ME, Kelley AE (2009). Muscarinic receptor antagonism causes a functional alteration in nucleus accumbens mu-opiate-mediated feeding behavior. Behav Brain Res 197: 225-229.

Poyner DR, Sexton PM, Marshall I, Smith DM, Quirion R, Born W et al (2002). International Union of Pharmacology. XXXII. The mammalian calcitonin gene-related peptides, adrenomedullin, amylin, and calcitonin receptors. Pharmacol Rev 54: 233-246.

Rushing PA, Hagan MM, Seeley RJ, Lutz TA, Woods SC (2000). Amylin: a novel action in the brain to reduce body weight. Endocrinology 141: 850-853.

Sexton PM, Paxinos G, Kenney MA, Wookey PJ, Beaumont K (1994). In vitro autoradiographic localization of amylin binding sites in rat brain. Neuroscience 62: 553-567.

Singh-Franco D, Perez A, Harrington C (2011). The effect of pramlintide acetate on glycemic control and weight in patients with type 2 diabetes mellitus and in obese patients without diabetes: a systematic review and meta-analysis. Diabetes Obes Metab 13: 169-180. 
Smith KS, Berridge KC (2007). Opioid limbic circuit for reward: interaction between hedonic hotspots of nucleus accumbens and ventral pallidum. J Neurosci 27: 1594-1605.

Stratford TR, Kelley AE (1997). GABA in the nucleus accumbens shell participates in the central regulation of feeding behavior. J Neurosci 17: 4434-4440.

van Rossum D, Hanisch UK, Quirion R (1997). Neuroanatomical localization, pharmacological characterization and functions of CGRP, related peptides and their receptors. Neurosci Biobehav Rev 21: 649-678.

van Rossum D, Menard DP, Fournier A, St-Pierre S, Quirion R (1994). Autoradiographic distribution and receptor binding profile of [125I]Bolton Hunter-rat amylin binding sites in the rat brain. J Pharmacol Exp Ther 270: 779-787.

Williams JT, Ingram SL, Henderson G, Chavkin C, von Zastrow M, Schulz S et al (2013). Regulation of mu-opioid receptors: desensitization, phosphorylation, internalization, and tolerance. Pharmacol Rev 65: 223-254.

Woolley JD, Lee BS, Fields HL (2006). Nucleus accumbens opioids regulate flavor-based preferences in food consumption. Neuroscience 143: 309-317.

Zhang M, Kelley AE (1997). Opiate agonists microinjected into the nucleus accumbens enhance sucrose drinking in rats. Psychopharmacology (Berl) 132: 350-360.

Zhang M, Kelley AE (2000). Enhanced intake of high-fat food following striatal mu-opioid stimulation: microinjection mapping and Fos expression. Neuroscience 99: 267-277.

Ziauddeen H, Chamberlain SR, Nathan PJ, Koch A, Maltby K, Bush $\mathrm{M}$ et al (2013). Effects of the mu-opioid receptor antagonist GSK1521498 on hedonic and consummatory eating behaviour: a proof of mechanism study in binge-eating obese subjects. Mol Psychiatry 18: 1287-1293. 